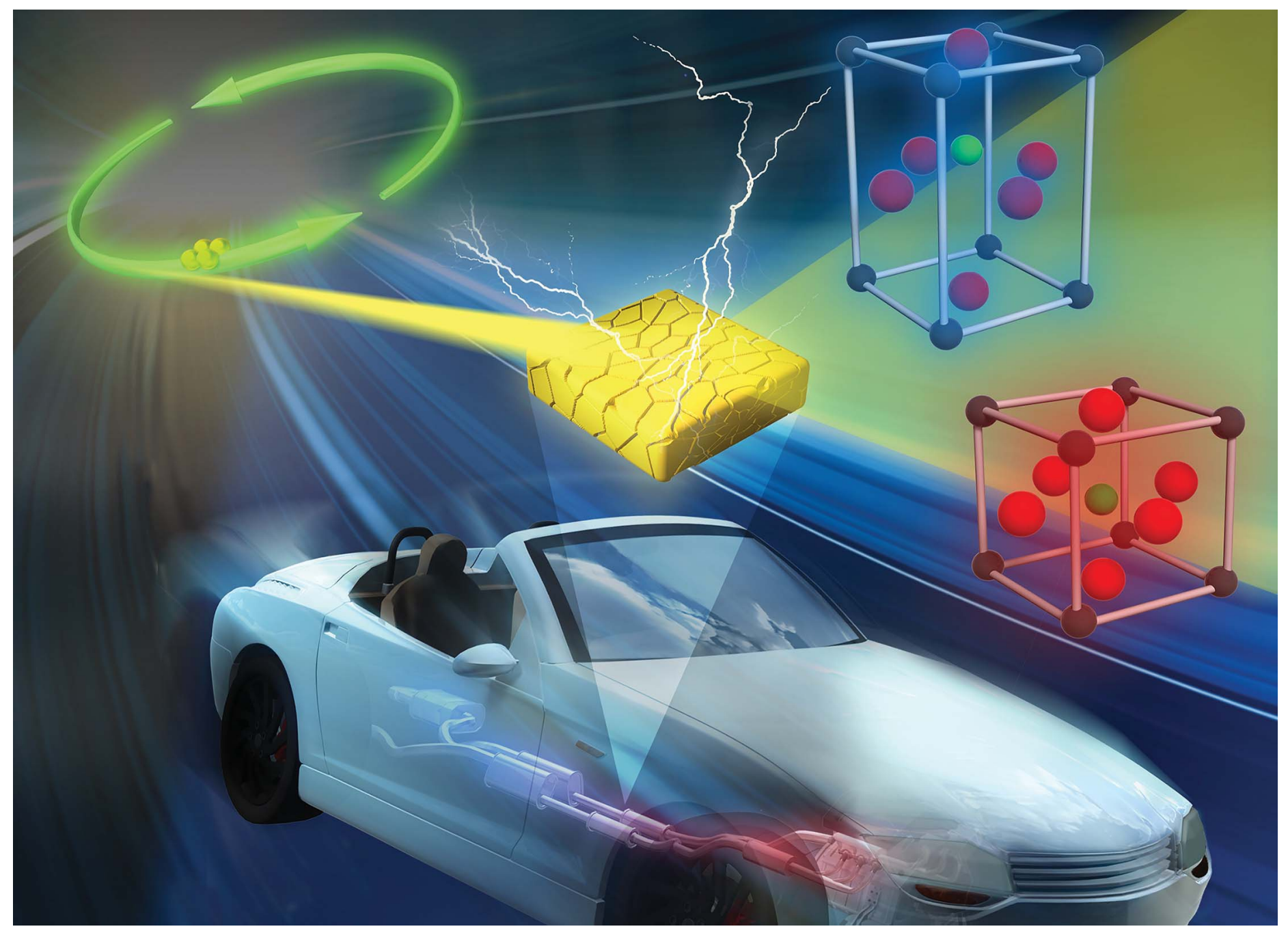

Showcasing research from Dr. Kim's group of Advanced R\&D Department, Daihatsu Motor Co., Ltd., Shiga, Japan, and co-workers.

Pyroelectric power generation from the waste heat of automotive exhaust gas

In this article, Niobium-doped lead zirconate titanate stannate (PNZST) ceramics are applied as pyroelectric materials, and their characteristics of electric power generation are investigated using real exhaust gas. To get the practical energy, the temporal temperature variations (pyroelectric effect) have been applied instead of the spatial temperature gradient (Seebeck effect) normally used with thermoelectric systems. The original electro-thermodynamic cycle and the novel system are expected to be viable in any heat sources with time-dependent temperature changes.

\section{As featured in:}

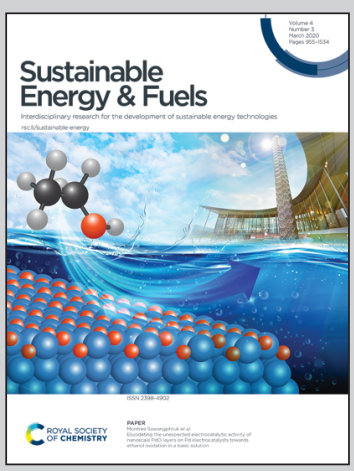

See Yoonho Kim et al., Sustainable Energy Fuels, 2020, 4, 1143. 
Check for updates

Cite this: Sustainable Energy Fuels, 2020, 4, 1143

Received 6th May 2019

Accepted 7th October 2019

DOI: $10.1039 / c 9 s e 00283 a$

rsc.li/sustainable-energy

\title{
Pyroelectric power generation from the waste heat of automotive exhaust gas
}

\author{
Juyoung Kim, ${ }^{a}$ Satoru Yamanaka, ${ }^{a}$ Ichiro Murayama, ${ }^{a}$ Takanori Katou, ${ }^{a}$

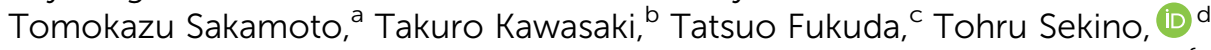 \\ Tadachika Nakayama, ${ }^{e}$ Masatoshi Takeda, ${ }^{e}$ Masaaki Baba, ${ }^{e}$ Hirohisa Tanaka,

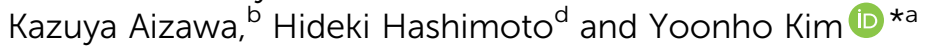

\begin{abstract}
Waste heat is a potentially exploitable energy source but remains a problem awaiting a solution. To explore solutions for automobile applications, we investigate pyroelectric power generation from the temperature variation of exhaust gas using a novel electro-thermodynamic cycle. Niobium-doped lead zirconate titanate stannate (PNZST) ceramics were applied as pyroelectric materials, and their structural characteristics were investigated. In the driving cycle assessments (JC-08) using real exhaust gas, the maximum power generated was identified as $143.9 \mathrm{~mW} \mathrm{~cm}^{-3}\left(777.3 \mathrm{~J} \mathrm{~L}^{-1}\right.$ per 1 cycle) over a temperature range of $150-220{ }^{\circ} \mathrm{C}$ and an electric field of $13 \mathrm{kV} \mathrm{cm}^{-1}$. The net mean generating power of the total driving cycle was $40.8 \mathrm{~mW} \mathrm{~cm}^{-3}$, which is the most enhanced result in our power generating systems to date and 314 times greater than our first report. Materials with sharp transition behaviors with the temperature and electric field are worthy of study with regard to pyroelectric energy harvesting materials, and their corresponding crystal and domain structures were investigated to optimize performance.
\end{abstract}

\section{Introduction}

Research and interest in types of energy conversion that would otherwise be overlooked have increased as the energy demands of society continue to grow. In 2011, approximately $58 \%$ of the energy consumed was lost as waste heat across the world, and that in the transportation sector accounted for $34.5 \%$ of the total loss. ${ }^{2}$ In automobiles, a given amount of waste heat is lost from exhaust gas, and the temperature of exhaust gas varies temporally corresponding to the cycling of an internal combustion engine or driving conditions. Such a temporal temperature variation ( $\mathrm{d} T / \mathrm{d} t$, where $t$ is time) can be utilized as thermoelectric energy, which can be harvested to be converted into electrical energy, ${ }^{3-6}$ known as the pyroelectric effect $(\mathrm{PE}) .^{7}$

${ }^{a}$ Advanced Research and Development Department, Daihatsu Motor Co., Ltd, 3000, Yamanoue, Ryuo, Gamo, Shiga, 520-2593, Japan. E-mail: Yoonho_Kim@dk. daihatsu.co.jp; Fax: +81-74-857-1064; Tel: +81-74-857-1685

${ }^{b} J$-PARC Center, Japan Atomic Energy Agency, 2-4 Shirane Shirakata, Tokai, Naka, Ibaraki, 319-1195, Japan

${ }^{c}$ Materials Sciences Research Center, Japan Atomic Energy Agency, 1-1-1, Kouto, Sayo, Hyogo, 679-5148, Japan

${ }^{d}$ The Institute of Scientific and Industrial Research (ISIR), Osaka University, Mihogaoka 8-1, Osaka, Ibaraki, 567-0047, Japan

${ }^{e}$ Nagaoka University of Technology, 1603-1, Kamitomioka, Nagaoka, Niigata, 9402188, Japan

${ }^{f}$ Kwansei Gakuin University, 2-1 Gakuen, Sanda, Hyogo, 669-1337, Japan
Pyroelectric materials that exhibit a PE have a polar symmetry in their crystal structure, leading to spontaneous polarization $\left(P_{\mathrm{S}}\right)$. As the temperature increases, these materials undergo phase transitions from the ferroelectric phase to the paraelectric phase as $P_{\mathrm{S}}$ changes. The decrease in polarization of the materials can be recovered as electrical work from the thermodynamic cycle. Perovskite structures such as $\mathrm{Pb}(\mathrm{Zr}, \mathrm{Ti}) \mathrm{O}_{3}$ (PZT) and $\mathrm{Pb}\left(\mathrm{Mg}_{1 / 3} \mathrm{Nb}_{2 / 3}\right) \mathrm{O}_{3}-\mathrm{PbTiO}_{3}$ (PMN-PT)-based ceramics have been utilized in many studies for energy harvesting due to their outstanding electrical properties. Pandya et al. ${ }^{8}$ reported that a maximum energy density and power density of $1.06 \mathrm{~J}$ $\mathrm{cm}^{-3}$ and $526 \mathrm{~W} \mathrm{~cm}^{-3}$, respectively, were scaled for ferroelectric PMN-PT thin films from the implementation of Ericsson cycles. Kim et al. ${ }^{1}$ reported the practical application of pyroelectric power generation using PZT-based ceramics for exhaust gas of an automobile by using a novel electro-thermodynamic cycle.

To improve the efficiency of power generation, the development of pyroelectric materials through diversified analysis is required. In this report, following previous studies, ${ }^{\mathbf{1 , 9 - 1 2}}$ a practical assessment of the power generation performance was conducted using an engine dynamometer, for which we obtained considerably improved results with niobium-doped lead zirconate titanate stannate $\left(\mathrm{Pb}_{0.99} \mathrm{Nb}_{0.02}\left(\mathrm{Zr}_{0.637} \mathrm{Sn}_{0.273^{-}}\right.\right.$ $\left.\mathrm{Ti}_{0.09}\right)_{0.98} \mathrm{O}_{3}$, PNSZT) ceramics. This material was characterized and investigated with respect to its phase structure and transition behavior in the cycles to discuss the proper direction of 
materials research in the pyroelectric power generation system.

\section{Novel electro-thermodynamic cycle}

From the perspective of the temperature and electric field, the electro-thermodynamic cycle using the PE can be described by the loop of the electric displacement of materials. Fig. 1 illustrates the electrical polarization $(D)$ change in a pyroelectric material with electric field $(E)$ at high temperature $\left(T_{\mathrm{H}}\right)$ and low temperature $\left(T_{\mathrm{L}}\right)$. The Olsen cycle proposed by Olsen et al. ${ }^{\mathbf{1 3 - 1 6}}$ consists of an A-B-C-D loop using two isoelectric and two isothermal processes. The generating power density $\left(P_{\mathrm{D}}, \mathrm{W} \mathrm{L}^{-1}\right)$ in this system can be calculated according to the formula

$$
P_{\mathrm{D}}=N_{\mathrm{D}} f
$$

where $N_{\mathrm{D}}$ (J per L per cycle) is the energy density per unit volume per unit cycle and $f$ is the frequency of the cycle. For realization of the cycle in a practical device environment, in this study, a novel electro-thermodynamic cycle $\left(\mathrm{A}-\mathrm{B}-\mathrm{C}_{1}-\mathrm{D}\right)$ is used based on temporal temperature variation to obtain the practical net energy. ${ }^{\mathbf{1 , 1 2}}$ In Fig. 1(b), a simple pseudosinusoidal wave of temperature was considered, imaged from the temperature fluctuation of the exhaust gas. Two kinds of electric field are plotted: the electric field of materials with a dashed purple line and an external electric field (electric field of the amplifier, $E_{\mathrm{H}}$ ) with a solid purple line. The experimental details are as follows.

STEP 1 (A-B): the external electric field $\left(E_{\mathrm{H}}\right)$ is applied briefly to the sample when the temperature begins to increase, and the sample reaches maximum polarization.

STEP 2 (at point B): $E_{\mathrm{H}}$ is removed by the diode when charging is completed.

STEP $3\left(\mathrm{~B}-\mathrm{C}_{1}\right)$ : in this period, we can obtain an additional voltage increase in the sample. The material is then isolated in the circuit (Fig. 1(c)), and the electric displacement $D$ is kept constant while the temperature increases to $T_{\mathrm{H}}$. The internal electric field of the materials (dashed line) is increased along path $\mathrm{BC}_{1}$ based on the electro-thermodynamic equation $\mathrm{d} D / \mathrm{d} t=$ $\varepsilon \mathrm{d} E / \mathrm{d} t-p \mathrm{~d} T / \mathrm{d} t$ (where $D, E, T, \varepsilon, t$ and $p$ are the electric displacement, electric field, temperature, dielectric permittivity, time, and pyroelectric coefficient, respectively).

STEP $4\left(\mathrm{C}_{1}-\mathrm{D}\right)$ : when the temperature begins to decrease, the switch is turned on and charged electricity immediately flows to R1 and R2. Finally, the material is reconnected to the circuit.

STEP $5\left(\mathrm{D}-\mathrm{A}^{\prime}\right)$ : the D-E loop is closed by cooling back to $T_{\mathrm{L}}$ and moving to point A. After the electricity has finished decreasing, the temperature continues to decrease when the switch is opened.

STEP 6 (at point $\mathrm{A}^{\prime}$ ): the switch is turned off before the next cycle.

Fig. 1(c) shows a harvesting circuit with a diode and two switches (DSW) redesigned based on the general Sawyer-Tower (ST) circuit to divide the input/output energy by the inductions of the diode and switch resistance $\left(P_{\mathrm{P} 1}\right.$ and $P_{\mathrm{P} 2}$ for measuring
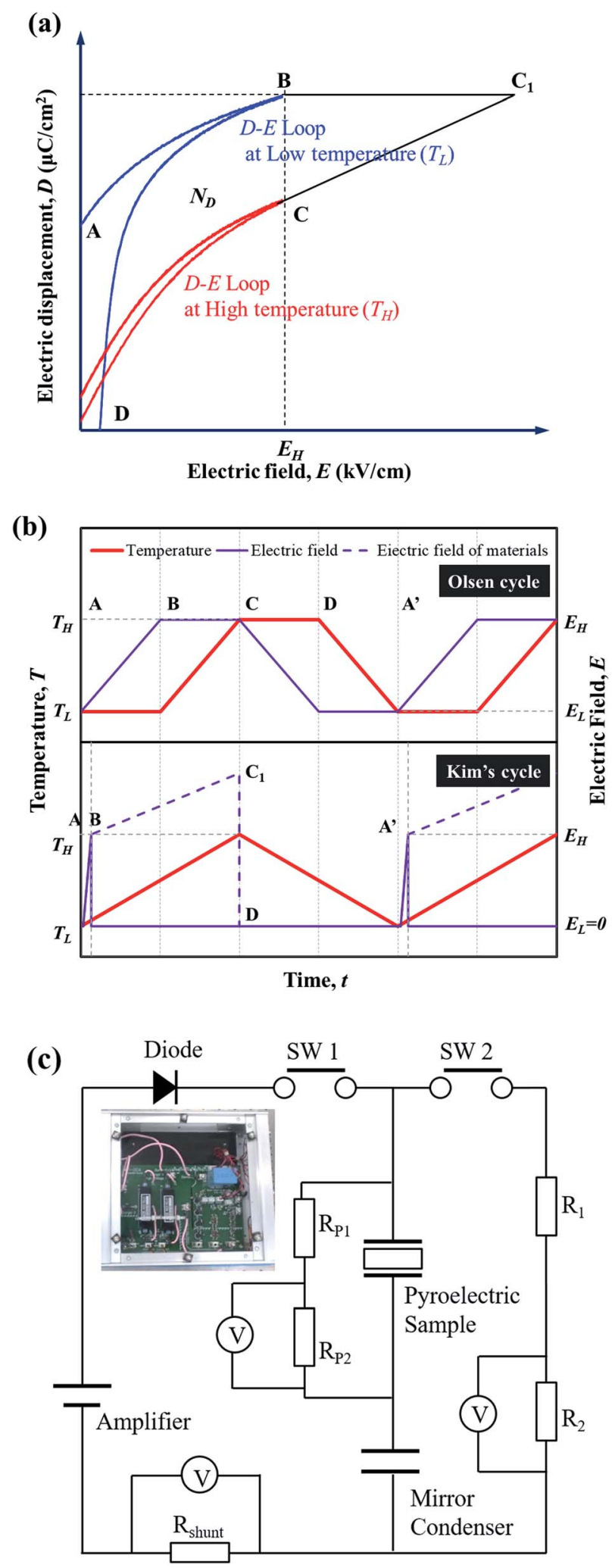

Fig. 1 (a) A schematic of bipolar D-E loops for a pyroelectric material at high and low temperature along with the novel electro-thermodynamic cycle, (b) the cycling conditions for the D-E loop, and (c) a harvesting circuit with a diode and two switches (DSW). 
the voltage of pyroelectric materials, and $R_{1}, R_{2}$ and $R_{\text {Shunt }}$ for calculating the net generating power).

\section{Experimental}

PNZST $\left(\mathrm{Pb}_{0.99} \mathrm{Nb}_{0.02}\left(\mathrm{Zr}_{0.637} \mathrm{Sn}_{0.273} \mathrm{Ti}_{0.09}\right)_{0.98} \mathrm{O}_{3}\right)$ ceramics with sizes of $30 \times 20 \times 0.5 \mathrm{~mm}^{3}$ were acquired from Murata Manufacturing Co., Ltd. For analysis of the crystal structure, neutron powder diffraction patterns were collected using a high-resolution neutron powder diffractometer (BL19 Takumi) in the Materials and Life Science Experimental Facility at J-PARC. The collected data were analyzed by the Rietveld method using the software Z-Rietveld. Transmission electron microscopy (TEM) observations using a real working environmental electron holography microscope (JEM-ARM200F-B, JEOL) were conducted at the National Institute for Materials Science (NIMS). For in situ experiments, Aduro in situ heating and an electrical biasing holder (Protochips Inc.) with a fusion electrothermal E-chip (E-FXA) were equipped. The bipolar electric-hysteresis loops for the PNZST sample were also measured using an impedance analyzer.

For power generation tests in the laboratory, a DSW circuit (Fig. 1(c)) was used as an energy-harvesting circuit.,12 To simulate engine exhaust gas, two heat blowers (Hot Wind System, LEISTER) and a mechanical cylinder (ELCM4E10MKAP, Oriental Motor) were employed. In the pseudosinusoidal temperature variation with a period of $0.05 \mathrm{~Hz}$, the $T_{\mathrm{H}}$ ranged from 100 to $200{ }^{\circ} \mathrm{C}$ with a temperature difference of $\Delta T=T_{\mathrm{H}}-$ $T_{\mathrm{L}}=40{ }^{\circ} \mathrm{C}$, and the electric field was applied using a highvoltage amplifier $(677 \mathrm{~B}$, TREK), synchronized to the pseudosinusoidal temperature variation.

A virtual vehicle simulator using an engine dynamometer based on exhaust gas (660cc, KF-VE3, Daihatsu Motor Co. Ltd. ${ }^{17}$ ) was used to evaluate the generating performance of the materials in a real environment, as shown in Fig. 2. The material was set into a special module case in the exhaust pipe with the circuit connected. The generating test was performed based on the Japanese fuel-economy and emission test driving cycle (JC08 mode). ${ }^{17,18}$

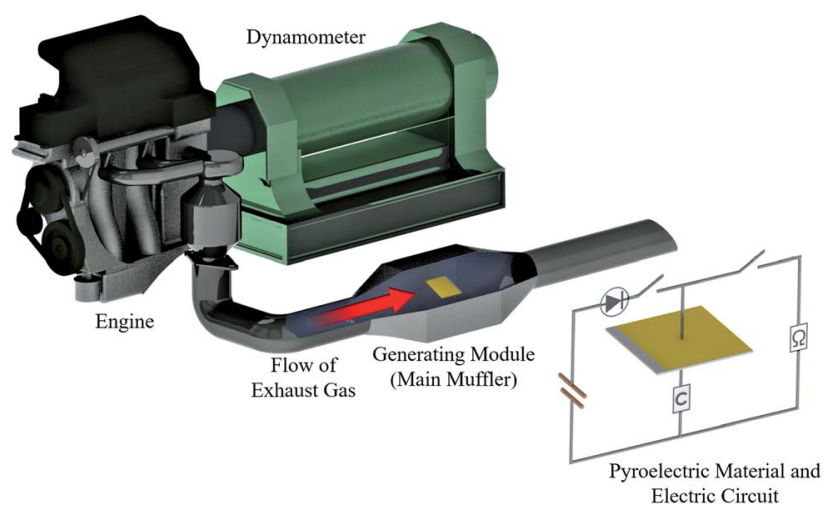

Fig. 2 A schematic diagram of the engine dynamometer assessment (Daihatsu, home-made). The pyroelectric material is set inside the generating module (main muffler).

\section{Results and discussion}

Fig. 3(a) shows the time-of-flight (TOF) neutron powder diffraction pattern for the PNZST powder in the $d$-spacing range of $0.5-3.2 \AA$, as well as the crystal structure drawn using the VEST software.$^{19}$ According to the Rietveld refinement, the diffraction peaks of PNZST were fitted and characterized by the rhombohedral unit cell with the space group $R 3 c$. The lattice parameters were calculated to be $a=b=c=5.82938(2)$ $\AA, \alpha=\beta=\gamma=59.7995(4)^{\circ}$ in a rhombohedral lattice. Crystallographic data for PNZST were also obtained, as listed in Table 1.

Fig. 3(b) presents the microstructure obtained from TEM observations. The anisotropic domains were less than $50 \mathrm{~nm}$ thick and had hierarchical lamellar-like structures. The high

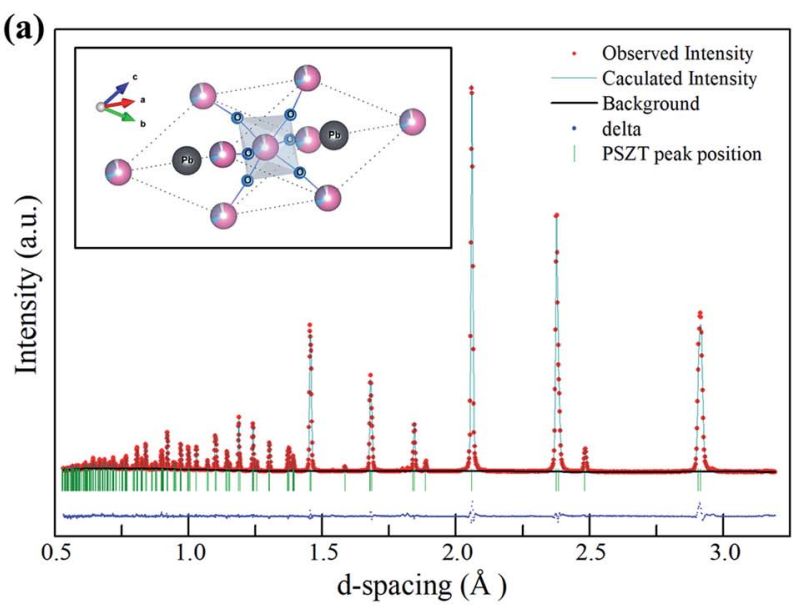

(b)

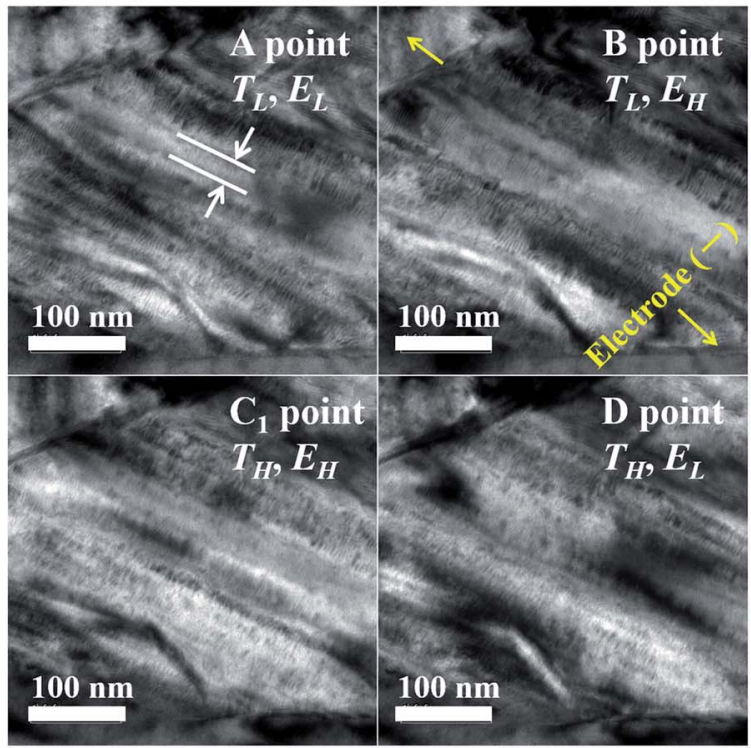

Fig. 3 (a) Refined profiles of a sample at room temperature from the powder using neutron diffraction data and the crystal structure of the $R 3 c$ phase for PNZST, and (b) the microstructures of PNZST ceramics observed by in situ transmission electron microscopy (TEM) experiments. 
Table 1 Atomic parameters for PNZST from Rietveld refinement at room temperature. The calculated profiles of fit are $R_{\mathrm{p}}: 4.07$ and $R_{\mathrm{wp}}$ : 5.73

\begin{tabular}{lllll}
\hline Atom & $x$ & $y$ & $z$ & $B$ \\
\hline $\mathrm{Pb}$ & $0.23281(5)$ & $0.23281(5)$ & $0.23281(5)$ & $1.414(11)$ \\
$\mathrm{Nb} / \mathrm{Zr} / \mathrm{Sn} / \mathrm{Ti}$ & 0 & 0 & 0 & $0.280(14)$ \\
$\mathrm{O}$ & $0.28287(11)$ & $0.22625(12)$ & $0.77480(14)$ & $2.053(17)$
\end{tabular}

density of nanoscale domains occurred due to small domain wall energies, which could facilitate the reorientation of polarization..$^{20}$ In situ experiments were performed along the individual cycle points A, B, $\mathrm{C}_{1}$ and D in Fig. 1(b). According to the $T_{\mathrm{H}}$ and $E_{\mathrm{H}}$ variations, the reversible response to the temperature and external electric field of the domains was confirmed.

Fig. 4(a) shows the temperature dependence of D-E hysteresis loops for the ceramics. The spontaneous polarization $\left(P_{\mathrm{s}}\right)$ and remnant polarization $\left(P_{\mathrm{r}}\right)$ respectively reached 34.32 and $29.79 \mu \mathrm{C} \mathrm{cm}^{-2}$ and the coercive field $\left(E_{\mathrm{c}}\right)$ reached

(a)

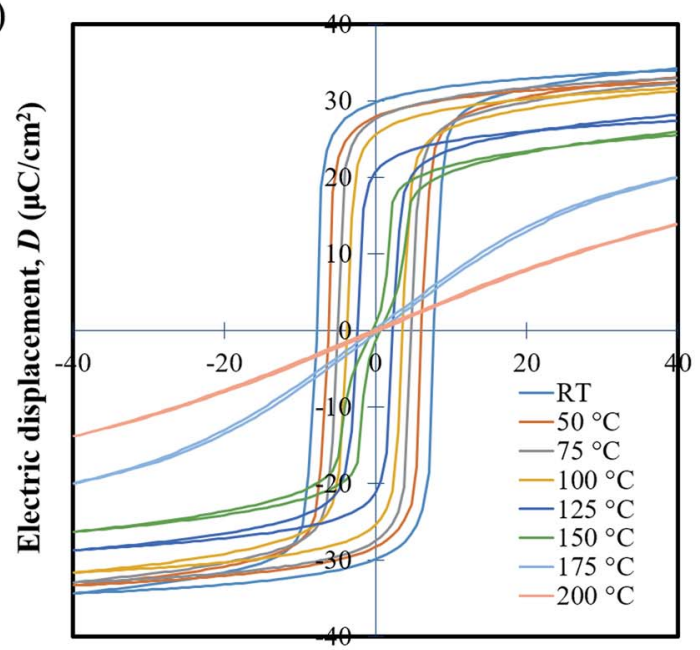

Electric field, $E(\mathrm{kV} / \mathrm{cm})$

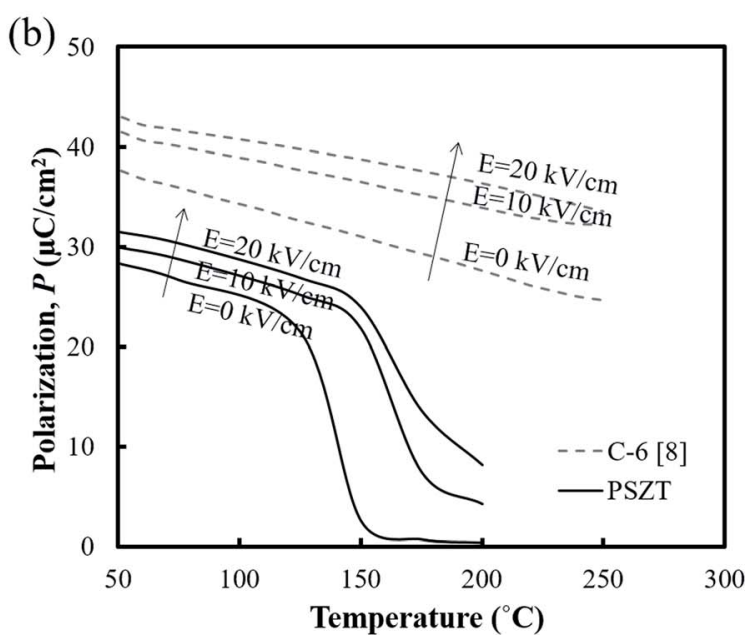

Fig. 4 (a) Hysteresis D-E loops and (b) the polarizations of the PNZST ceramic as a function of temperature.
$7.63 \mathrm{kV} \mathrm{cm}^{-1}$ at room temperature, indicating square loops typical of a ferroelectric (FE) state. The $P_{\mathrm{s}}, P_{\mathrm{r}}$ and $E_{\mathrm{c}}$ decreased with temperature, and the antiferroelectric (AFE) region could be found shortly with double loop hysteresis in the vicinity of $150{ }^{\circ} \mathrm{C}$ before slim loops of a paraelectric state (PE) appeared. When an electric field above $5 \mathrm{kV} \mathrm{cm}{ }^{-1}$ is applied while the temperature increases, the materials have a FE-PE phase transformation according to the temperature without going through the AFE phase. Berlincourt et al. ${ }^{21}$ confirmed the phase diagram of $\mathrm{Pb}_{0.99} \mathrm{Nb}_{0.02}\left(\mathrm{Zr}_{0.73} \mathrm{Sn}_{0.27} \mathrm{Ti}_{0.07}\right)_{0.98} \mathrm{O}_{3}$ ceramics with the electric field and demonstrated that the incipient AFE state acts to increase the slope of the FE-PE boundary. As shown in Fig. 4(b), the polarizations of PNZST ceramics as a function of temperature decrease sharply while undergoing phase transformation corresponding to the D-E
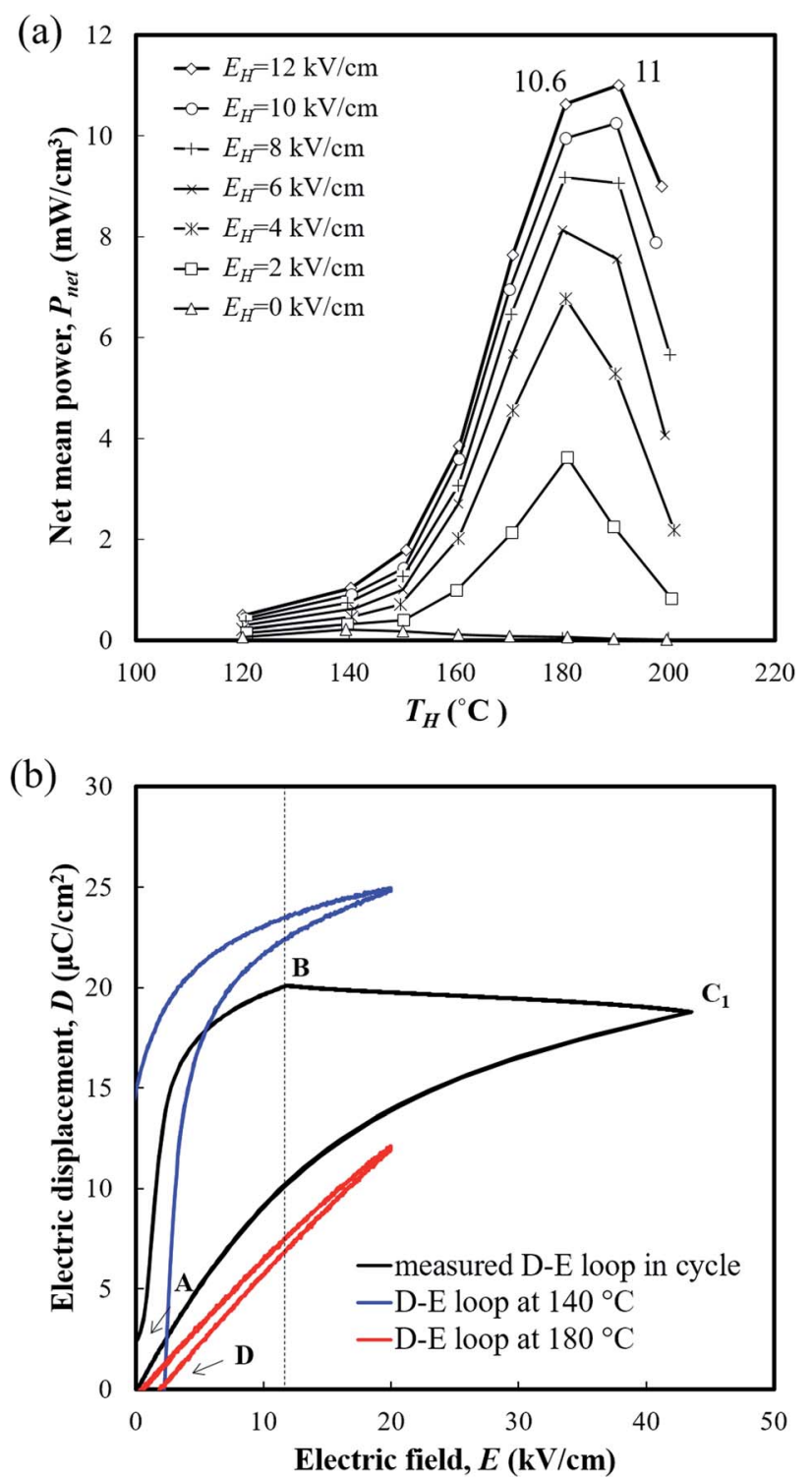

Fig. 5 (a) Temperature dependence of the net mean power of PNZST samples in the laboratory generating assessments. $\Delta T$ was $40{ }^{\circ} \mathrm{C}$ in all ranges; (b) results of the theoretical generating potential evaluation with PNZST samples at $T_{\mathrm{H}}=180{ }^{\circ} \mathrm{C}$ and $E_{\mathrm{H}}=12 \mathrm{kV} \mathrm{cm}^{-1}$. 
loop results. The sharp polarization behavior of PNZST compared to that in our previous study (C-6, PZT-based ceramics $)^{1}$ can be expected due to the atomic ordering in the lattice $^{22,23}$ and phase state under cycles. ${ }^{2,25}$ A rhombohedral phase has more available orientations for polarizations than a tetragonal phase such as the C-6 sample, leading to a naturally softer domain reorientation. This means that the rhombohedral state is relatively liable to rotate polarization with a small $E_{\mathrm{c}}$ and can maximize the energy generation by reducing the input energy.

The generating performance was evaluated using the DSW circuit in Fig. 1(c). The temperature variation $\Delta T\left(=T_{\mathrm{H}}-T_{\mathrm{L}}\right)$ was set to be $40{ }^{\circ} \mathrm{C}$ considering the average temperature variation of the practical mode environment, and $E_{\mathrm{H}}$ reached up to $12 \mathrm{kV} \mathrm{cm}{ }^{-1}$ under each temperature condition. Fig. 5(a) presents the net mean power $\left(P_{\text {net }}\right)$ generated by PNZST samples according to $T_{\mathrm{H}}$ and $E$. The peak of $P_{\text {net }}$ was obtained when the $T_{\mathrm{H}}$ was near $180{ }^{\circ} \mathrm{C}$ (temperature range between $140{ }^{\circ} \mathrm{C}$ and $180{ }^{\circ} \mathrm{C}$ ), including the $\mathrm{FE}-\mathrm{PE}$ transition region in which the largest change in polarization occurred due to depolarization of the material above the transition temperature. ${ }^{26}$ As higher $E_{\mathrm{H}}$ was applied, the $P_{\text {net }}$ increased and the temperature of the $P_{\text {net }}$ peak became higher. This indicates that the temperature of the FE-PE transition increase was a function of $E_{\mathrm{H}} \cdot{ }^{21}$ The maximum $P_{\text {net }}$ observed was $11 \mathrm{~mW} \mathrm{~cm}^{-3}$ (generating energy of $220 \mathrm{~J} \mathrm{~L}^{-1}$ per 1 cycle) at $T_{\mathrm{H}}=190{ }^{\circ} \mathrm{C}$ (temperature range between $150{ }^{\circ} \mathrm{C}$ and $190{ }^{\circ} \mathrm{C}$ ), which is a significantly enhanced value compared to the PZTbased ceramics in our previous study (C-9: $0.16 \mathrm{~mW} \mathrm{~cm}^{-1}$ ). Above $T_{\mathrm{H}}=190{ }^{\circ} \mathrm{C}$, the change in polarization decreased, which resulted in the degradation of $P_{\text {net }}$.

Fig. 5(b) shows the measured D-E behavior of PNZST samples undergoing the generating cycle (at $T_{\mathrm{H}}=180^{\circ} \mathrm{C}$ and $E_{\mathrm{H}}=12 \mathrm{kV} \mathrm{cm}^{-1}$ ), which is calculated from the charge of the connected capacitor. Compared to the theoretical area of the isothermal D-E loop, there are gaps in electrical displacements which are mainly due to cycling conditions. As shown in Fig. 1(b), when the $E_{\mathrm{H}}$ applied in the A-B process, the temperature of the material already increases, which makes a difference with regard to its theoretical isothermal behavior. The process $\mathrm{C}_{1}-\mathrm{D}$ also has losses because the material is undergoing the cooling step during the recovery of the

(a)

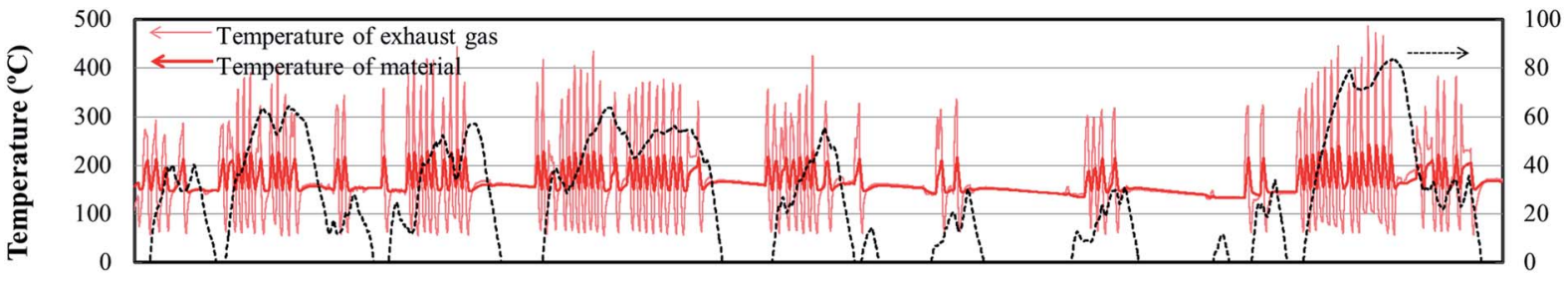

(b)

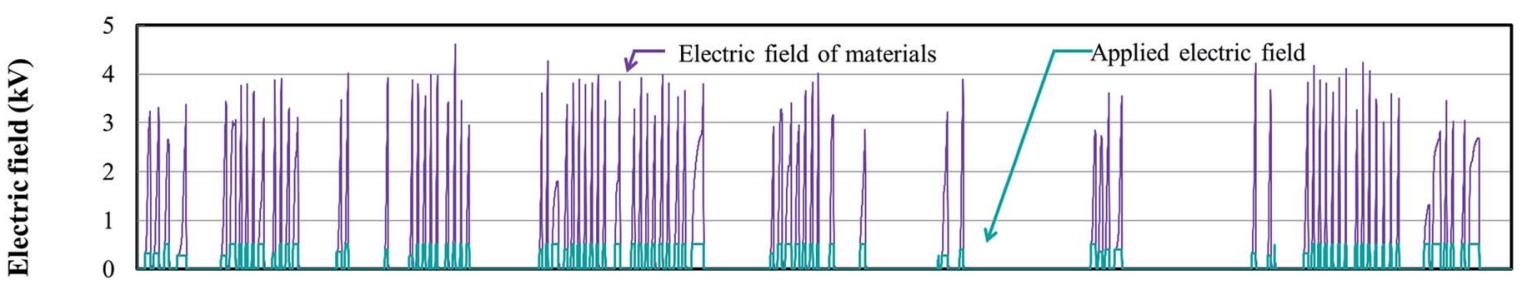

(c)
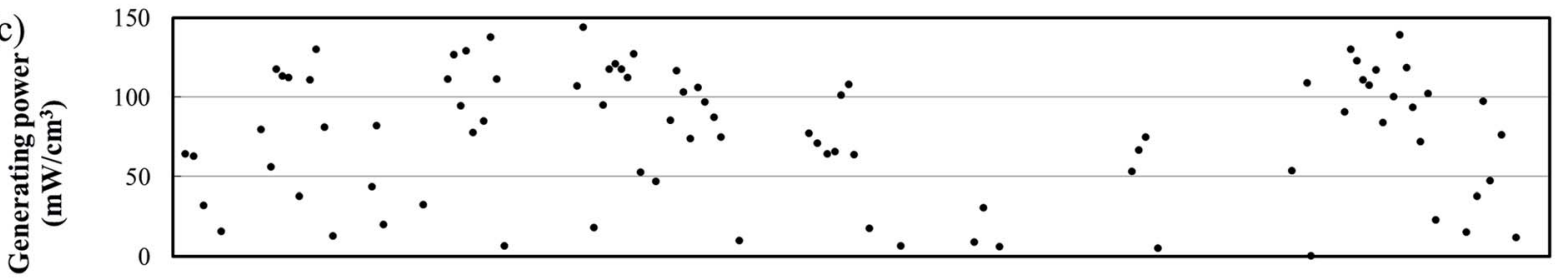

(d)
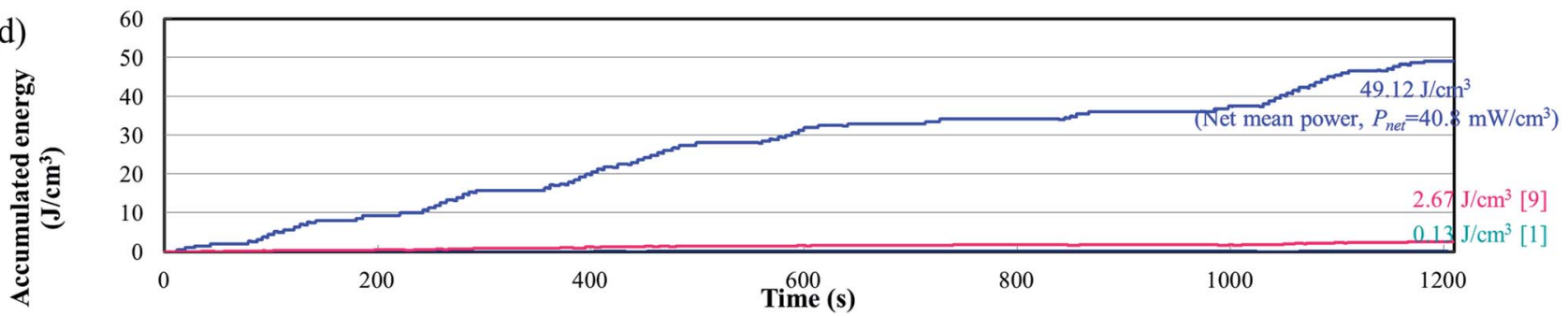

Fig. 6 Results of generating power assessments with a real engine dynamometer during the Japanese fuel-economy and emission test driving cycle (JC08 mode). (a) Temperature of exhaust gas (solid line), temperature of the material (bold line) and vehicle speed, (b) electric field of the material and the applied electric field, (c) individual calculated power of each temperature variation, and (d) accumulated generating energy over the total cycle. 
energies. On the other hand, at point $\mathrm{D}$, the polarization of the material vanishes above the FE-PE transformation temperature and a certain level of electric field is needed to realign the dipoles until the full repolarization of point B. Materials that are liable to rotate polarization have high slopes of the A-B route linked with their high power generating potential.

An engine dynamometer assessment using real exhaust gas was conducted based on the Japanese fuel-economy and emission test driving cycle (JC08 mode), as shown in Fig. 2. In the redesigned main muffler, the temperature of the exhaust gas was controlled to include the phase transition region of the PNZST samples, and the external $E_{\mathrm{H}}$ was optimized as 13 $\mathrm{kV} \mathrm{cm}{ }^{-1}$ for each representative temperature variation (Fig. 6(a) and (b)). Fig. 6(c) shows the individual calculated energy densities of each temperature variation in the mode. The maximum generating power was $143.9 \mathrm{~mW} \mathrm{~cm}^{-3}$ (generating energy of $777.3 \mathrm{~J} \mathrm{~L}^{-1}$ per 1 cycle) in the temperature range of 150-220 ${ }^{\circ} \mathrm{C}$ and the detailed cycle behavior is shown in Fig. 7. In

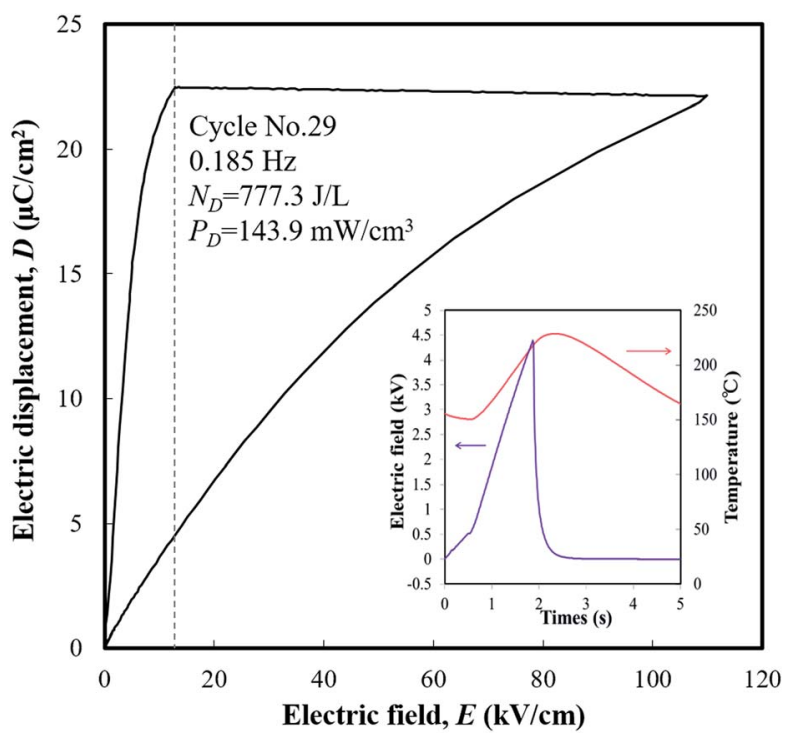

Fig. 7 The maximum generating power cycle in the test and its conditions: $T_{\mathrm{L}}=150{ }^{\circ} \mathrm{C}, T_{\mathrm{H}}=220^{\circ} \mathrm{C}$, and $E_{\mathrm{H}}=13 \mathrm{kV} \mathrm{cm}^{-1}$. this cycle, the speed condition of the vehicle is the range of about $0-40 \mathrm{~km} \mathrm{~h}^{-1}$ and the acceleration is about $10 \mathrm{~m} \mathrm{~s}^{-2}$. Fig. 6(d) presents the results of the assessments over the total drive cycle with PNZST samples compared to previous results. ${ }^{\mathbf{1}, 9}$ The net mean power was $40.8 \mathrm{~mW} \mathrm{~cm}^{-3}$ (accumulated generating energy of $49117.4 \mathrm{~J} \mathrm{~L}^{-1}$ ), which is the highest value produced by any material in our energy harvesting system to date $^{\mathbf{1 , 9 - 1 2}}$ and is 314 times greater than what we presented in our first report. ${ }^{1}$

The comparisons of the current maximum power and energy density for pyroelectric energy harvesting studies for various materials are shown in Table 2, together with the respective operating conditions. PNZST ceramics in this study have a sharp phase transition behavior with the temperature from the rhombohedral phase with many axes of polarization (the number of available orientations for the polarization in the lattice is eight in the rhombohedral phase and six in the tetragonal phase for pervious samples), and the polarization rotates easily with the external electric field with a small $E_{\mathrm{c}}$, such that enhanced power generating was obtained. These materials have enormous potential for high performance and can be advantageously utilized for many other device applications in addition to this automobile system. According to the practical system environment of devices, the generating power can be enhanced more by thinning the samples, controlling the temperature and frequency, and improving the breakdown voltage.

We consider that the high performance materials used for pyroelectric energy harvesting mostly have an appreciable change in polarization behavior in each cycle, as well as a corresponding crystal structure. In addition to this, we speculate that materials that are composed of nanoscale anisotropic domains and have many axes of rotatable dipoles have higher performance. An investigation of the structural changes in pyroelectric materials in terms of the crystal and domain scale is presented herein, and future research regarding energy harvesting will continue to address these characteristics for the design of high performance materials.

Table 2 Comparison of the pyroelectric power generation potentials in pyroelectric materials

\begin{tabular}{|c|c|c|c|c|c|c|}
\hline Material & $\begin{array}{l}\text { Temperature } \\
T_{\mathrm{H}} / T_{\mathrm{L}}\left({ }^{\circ} \mathrm{C}\right)\end{array}$ & $\begin{array}{l}\text { Electric field } E_{\mathrm{H}} / E_{\mathrm{L}} \\
\left(\mathrm{kV} \mathrm{cm}^{-1}\right)\end{array}$ & $\begin{array}{l}\text { Frequency of the } \\
\text { experimental cycle }(\mathrm{Hz})\end{array}$ & $\begin{array}{l}\text { Energy density } \\
\text { (J per L per cycle) }\end{array}$ & $\begin{array}{l}\text { Power density } \\
\left(\mathrm{mW} \mathrm{cm}^{-3}\right)\end{array}$ & Ref. \\
\hline PNZST ceramics & $220 / 150$ & $13 / 0$ & 0.185 & 777.3 & 143.9 & This study \\
\hline PZN-4.5 PT single crystals & $160 / 100$ & $20 / 0$ & 0.1 & 217 & 21.7 & 27 \\
\hline PMN-10PT ceramics & $80 / 30$ & $35 / 0$ & - & 186 & - & 28 \\
\hline PMN-32PT thin films & $\Delta T=56$ & $\Delta E=267$ & 1000 & 526 & 526000 & 8 \\
\hline PNZST ceramics & $177 / 157$ & $32 / 4$ & 0.26 & 131 & 34 & 29 \\
\hline PLZT ceramics & $160 / 25$ & $75 / 2$ & 0.0178 & 888 & 15.8 & 30 \\
\hline PNNZT ceramics & $220 / 20$ & $90 / 3$ & 0.09 & 867 & 78 & 5 \\
\hline $\mathrm{P}(\mathrm{VDF}-\mathrm{TrFE})$ thin films & $110 / 25$ & $500 / 200$ & 0.13 & 441 & 58 & 31 \\
\hline BCT-BZT-Fe ceramics & $110 / 30$ & $30 / 0$ & & 305 & - & 32 \\
\hline BNK-BST ceramics & $160 / 20$ & $40 / 1$ & Calculated from & 1523 & - & 33 \\
\hline BNKT ceramics & $110 / 25$ & $52 / 1$ & the $\mathrm{D}-\mathrm{E}$ diagram & 1986 & - & 34 \\
\hline PZT/CFO-L3 thin films & $27 /-173$ & $400 / 0$ & & 47372 & - & 35 \\
\hline
\end{tabular}




\section{Conclusion}

Experimental measurements of pyroelectric generating power were conducted for PNZST ceramics in a novel electrothermodynamic cycle. The PNZST ceramics underwent a phase transition from a ferroelectric state (rhombohedral structure with the space group $R 3 c$ ) to a paraelectric state in the cycle. The crystal structure influences the sharp transition behavior of electric displacement during changes in the temperature and electric field, resulting in enhanced power generating performance. In the virtual engine driving cycle, a net mean generating power of $40.8 \mathrm{~mW} \mathrm{~cm}^{-3}$ was obtained. To utilize pyroelectric energy harvesting in various applications, PNZST ceramics may be a promising candidate, but further experiments and investigations of the crystal structural transition behavior are necessary to better understand the factors of high power generating performance.

\section{Conflicts of interest}

There are no conflicts to declare.

\section{Acknowledgements}

The authors are thankful to Murata Manufacturing Co., Ltd. for providing the materials. Neutron diffraction experiments were performed using a neutron instrument at the MLF Pulsed Neutron Source at J-PARC (Proposal No. 2018I0019). A part of this work was supported by the NIMS microstructural characterization platform as a program of the "Nanotechnology Platform" of the Ministry of Education, Culture, Sports, Science and Technology (MEXT), Japan (Proposal No. A-16-NM-0196, A-17-NM0119, and A-18-NM-0081). Also, this work was supported by the New Energy Industrial Technology Development Organization (NEDO) through the Advanced Research Program for Energy and Environmental Technologies (Grant No. 17100185-0).

\section{References}

1 Y. Kim, J. Kim, S. Yamanaka, A. Nakajima, T. Ogawa, T. Serizawa, H. Tanaka, M. Baba, T. Fukuda, K. Yoshii, M. Takeda, N. Yamada, T. Nakayama and K. Niihara, Adv. Energy Mater., 2015, 5, 1401942.

2 World Energy Flow, in 2011, https:/flowcharts.llnl.gov/ commodities/energy, accessed February 2019.

3 S. P. Alpay, J. Mantese, S. Trolier-McKinstry, Q. Zhang and R. W. Whatmore, MRS Bull., 2014, 39, 1099-1111.

4 C. R. Bowen, J. Taylor, E. LeBoulbar, D. Zabek, A. Chauhan and R. Vaish, Energy Environ. Sci., 2014, 7, 3836-3856.

5 A.-S. Siao, I. M. McKinley, C.-K. Chao, C.-C. Hsiao and L. Pilon, J. Appl. Phys., 2018, 124, 174104.

6 C. R. Bowen, J. Taylor, E. Le Boulbar, D. Zabek and V. Y. Topolov, Mater. Lett., 2015, 138, 243-246.

7 W. H. Clingman and R. G. Moore Jr, J. Appl. Phys., 1961, 32, 675-681.

8 S. Pandya, J. Wilbur, J. Kim, R. Gao, A. Dasgupta, C. Dames and L. W. Martin, Nat. Mater., 2018, 17, 432-438.
9 S. Yamanaka, J. Kim, A. Nakajima, T. Katou, Y. Kim, T. Fukuda, K. Yoshii, Y. Nishihata, M. Baba, N. Yamada, T. Nakayama, M. Takeda, K. Niihara and H. Tanaka, Adv. Sustainable Syst., 2017, 1, 1600020.

10 J. Kim, S. Yamanaka, A. Nakajima, T. Katou, Y. Kim, T. Fukuda, K. Yoshii, Y. Nishihata, M. Baba, M. Takeda, N. Yamada, T. Nakayama, K. Niihara and H. Tanaka, Ferroelectrics, 2017, 512, 92-99.

11 J. Kim, T. Moro, J. Kim, S. Yamanaka, I. Murayama, T. Katou, T. Nakayama, M. Takeda, N. Yamada, Y. Nishihata, T. Fukuda, H. Tanaka, T. Sekino and Y. Kim, J. Alloys Compd., 2018, 768, 22-27.

12 J. Kim, S. Yamanaka, A. Nakajima, T. Katou, J. Kim, Y. Kim, T. Fukuda, K. Yoshii, Y. Nishihata, M. Baba, M. Takeda, N. Yamada, T. Nakayama and H. Tanaka, Adv. Sustainable Syst., 2018, 2, 1800067.

13 R. B. Olsen, J. M. Briscoe, D. A. Bruno and W. F. Butler, Ferroelectrics, 1981, 38, 975-978.

14 R. B. Olsen and D. D. Brown, Ferroelectrics, 1982, 40, 17-27. 15 R. B. Olsen and D. Evans, J. Appl. Phys., 1983, 54, 5941-5944. 16 R. B. Olsen, D. A. Bruno and J. M. Briscoe, J. Appl. Phys., 1985, 58, 4709-4716.

17 T. Serizawa, I. Tan and H. Tanaka, JSAE Rev., 1998, 52, 39-45. 18 Y. Kim, K. Naito, H. Fujikawa, T. Ogawa, I. Tan, K. Hasegawa and H. Tanaka, SAE Technical Paper, 2007.

19 K. Momma and F. Izumi, J. Appl. Crystallogr., 2008, 41, 653-658. 20 Y. M. Jin, Y. U. Wang, A. G. Khachaturyan, J. F. Li and D. Viehland, J. Appl. Phys., 2003, 94, 3629-3640.

21 D. Berlincourt, H. H. A. Krueger and B. Jaffe, J. Phys. Chem. Solids, 1964, 25, 659-674.

22 A. S. Bhalla, R. Guo and R. Roy, Mater. Res. Innovations, 2000, 4, 3-26.

23 N. Setter and L. E. Cross, J. Appl. Phys., 1980, 51, 4356-4360. 24 D. V. Taylor and D. Damjanovic, J. Appl. Phys., 1997, 82, 1973-1975.

25 M. I. Morozov, M.-A. Einarsrud, J. R. Tolchard, P. T. Geiger, K. G. Webber, D. Damjanovic and T. Grande, J. Appl. Phys., 2015, 118, 164104.

26 R. Kandilian, A. Navid and L. Pilon, Smart Mater. Struct., 2011, 20, 055020.

27 A. Khodayari, S. Pruvost, G. Sebald, D. Guyomar and S. Mohammadi, IEEE Trans. Ultrason. Eng., 2009, 56, 693-699.

28 G. Sebald, S. Pruvost and D. Guyomar, Smart Mater. Struct., 2007, 17, 015012.

29 R. B. Olsen, D. A. Bruno, J. M. Briscoe and J. Dullea, Ferroelectrics, 1984, 59, 205-219.

30 F. Y. Lee, S. Goljahi, I. M. McKinley, C. S. Lynch and L. Pilon, Smart Mater. Struct., 2012, 21, 025021.

31 A. Navid and L. Pilon, Smart Mater. Struct., 2011, 20, 025012. 32 D. Sharma, S. Patel, A. Singh and R. Vaish, Journal of Asian Ceramic Societies, 2016, 4, 102-111.

33 G. Vats, R. Vaish and C. R. Bowen, J. Appl. Phys., 2014, 115, 013505.

34 A. Chauhan, S. Patel, G. Vats and R. Vaish, Energy Technol., 2014, 2, 205-209.

35 G. Vats, A. Kumar, N. Ortega, C. R. Bowen and R. S. Katiyar, Energy Environ. Sci., 2016, 9, 1335-1345. 